\title{
Multivalent Presentation of Cationic Peptides on Supramolecular Nanofibers for Antimicrobial Activity
}

\author{
Mustafa Beter, ${ }^{\dagger}$ Hatice K. Kara, ${ }^{\dagger}$ Ahmet E. Topal, ${ }^{\dagger}$ Aykutlu Dana, ${ }^{\dagger}$ Ayse B. Tekinay, ${ }^{*}, \dagger, \ddagger$ \\ and Mustafa O. Guler*, ${ }^{*} \odot$ \\ ${ }^{\dagger}$ Institute of Materials Science and Nanotechnology, National Nanotechnology Research Center (UNAM), Bilkent University, Ankara \\ 06800, Turkey \\ ${ }^{\ddagger}$ Neuroscience Graduate Program, Bilkent University, Ankara 06800, Turkey \\ ${ }^{\S}$ Institute for Molecular Engineering, University of Chicago, Chicago, Illinois 60637, United States
}

\section{Supporting Information}

\begin{abstract}
Noncovalent and electrostatic interactions facilitate the formation of complex networks through molecular self-assembly in biomolecules such as proteins and glycosaminoglycans. Self-assembling peptide amphiphiles (PA) are a group of molecules that can form nanofibrous structures and may contain bioactive epitopes to interact specifically with target molecules. Here, we report the presentation of cationic peptide sequences on supramolecular nanofibers formed by self-assembling peptide amphiphiles for cooperative enhanced antibacterial activity. Antibacterial properties of self-assembled peptide nanofibers were significantly higher than soluble peptide molecules with identical amino acid sequences, suggesting that the tandem presentation of bioactive epitopes is important for designing new materials for bactericidal activity. In addition, bacteria were observed to accumulate more rapidly on peptide nanofibers compared to soluble peptides, which may further enhance antibacterial activity by increasing the number of peptide molecules interacting with the bacterial membrane. The cationic peptide amphiphile nanofibers were observed to attach to bacterial membranes and disrupt their integrity. These results demonstrate that short cationic peptides show a significant improvement in antibacterial activity when presented in the nanofiber form.
\end{abstract}

KEYWORDS: antibacterial peptide, cationic peptide, multivalent presentation, peptide nanofiber

\section{INTRODUCTION}

Antibiotics are commonly used for the treatment of bacterial infections in humans and domestic animals. ${ }^{1,2}$ However, extensive use and/or misuse of antibiotics may result in the development of antibiotic-resistant bacteria, which currently constitute a major health issue. ${ }^{3,4}$ The design of new antibiotics and administration methods to prevent the evolution of antibiotic resistance in pathogens is therefore of major interest and importance. However, new antibiotics are not developed as rapidly as needed, making delivery methods a greater priority for combating antibiotic-resistant bacteria., 5

Even though individual organisms may fail to thrive under adverse conditions, the species as a whole may survive if a beneficial mutation is produced in one of its members. Consequently, bacteria under stressful conditions downregulate the elements of their DNA repair mechanisms to produce more mutations, which may aid in acquiring resistance against antibiotic pressure. ${ }^{8}$ Bacteria in their natural environment are also exposed to uni- and multicellular competitors that produce a series of natural antibacterial agents. These natural antibacterial agents can keep the adaptive mechanisms of bacteria in check through an evolutionary arms race in which bacterial defenses to specific antibacterials are counteracted by changes in antibacterial-producing organisms. ${ }^{9,10}$ Use of these naturally evolved antibacterial agents is promising for development of novel drugs against bacteria. Antimicrobial peptides (AMPs), which are also called host defense peptides, are one of these ancient and successful strategies that occur in both plants and animals. ${ }^{11}$

Many of the natural AMPs are composed of short-sequences, exhibit an amphipathic structure consisting of both hydrophobic and hydrophilic domains, and carry overall net positive charges because of their lysine, arginine, and histidine residues. ${ }^{12}$ The initial interaction of AMPs with the bacterial membrane involves electrostatic attractions between positively charged peptides and negatively charged membranes. ${ }^{13,14}$ This first interaction is relatively nonspecific, as L- or D-enantiomers

Received: May 25, 2017

Revised: September 30, 2017

Accepted: October 11, 2017

Published: October 11, 2017 
of amino acids do not change their electrostatic interaction potential under experimental conditions. ${ }^{15}$ Following initial attachment, some AMPs are internalized and others function through membrane disruption. Although there are different biophysical models to explain the behavior of AMPs against bacterial membranes, passing a threshold concentration is generally considered to be necessary for action, ${ }^{16}$ with cationic AMPs usually working at higher concentrations. ${ }^{17}$ In addition, high-molecular weight peptides have a higher potential to be recognized and degraded by proteolytic enzymes, and the metabolic costs of antibacterial production also increase with protein size. Consequently, many natural antibacterials are small cationic peptides that can be produced at high concentrations at relatively low cost (in terms of both metabolic investment in living systems and monetary cost in human economics) and show greater bactericidal activity due to their ability to escape from proteolytic degradation. ${ }^{18}$

One of the disadvantages of AMPs compared to most antibiotic drugs is that, because of enzymatic degradation, the half-life of AMPs is significantly shorter than most antibiotics. ${ }^{19}$ However, a multivalent display method can increase the stability and half-life of peptides by intramolecular selfassembly. ${ }^{20,21}$ Self-assembly is convenient for combining different elements such as viral assembly and gene delivery with the antimicrobial effects of host defense peptides. ${ }^{22}$ Noncovalent interactions such as van der Waals, $\pi-\pi$, hydrogen bonding, and electrostatic interactions can create molecular attractions and promote self-assembly. ${ }^{23}$ Molecular self-assembly is used by nature for various tasks, foremost among which is the self-assembly of peptides, proteins, and membranes. Self-assembling peptides form into well-organized structures through hydrophobic and hydrophilic interactions, which improves the stability of the overall structure. ${ }^{24-26}$ Fibrous matrixes can be used as scaffold support for mammalian cell proliferation and provide resistance against bacterial colonization. ${ }^{27}$ Peptides with $\beta$-sheet secondary structures can be used for biomedical purposes such as space fillers for wound healing to prevent bacterial colonization. ${ }^{28}$ However, bacterial cell targeting is not the only property of cationic peptides. Translocation of phosphatidylserine and glycosylation differences cause cancer cell membranes to carry negative charges relative to healthy cell membranes, and cationic peptides target these membranes as in the case of bacterial membrane targeting efforts. $^{29}$ The $\beta$-sheet forming self-assembling peptide amphiphiles contain a hydrophobic tail, which induces formation of nanostructures through hydrophobic interactions in aqueous media, a $\beta$-sheet forming sequence, which is responsible for intermolecular hydrogen bonding, a hydrophilic sequence, which increases solubility of the individual molecules in water, and possible bioactive epitopes, which depend on the intended target of the peptide amphiphile molecule. ${ }^{30-32}$

Here, we demonstrate that the multivalent presentation of antibacterial peptides on self-assembled supramolecular nanofibers provides significant improvements in the context of antibacterial activity compared to single, soluble peptides. Antibacterial peptide nanofibers affect both Gram-positive and Gram-negative bacteria with improved antibacterial activity. In addition, while most natural linear amphipathic antimicrobial peptides form $\alpha$-helices when they bind to bacterial membranes, our design forms an amphipathic $\beta$-sheet structure. Therefore, this work provides additional information on the dynamics of $\beta$-sheet forming AMPs. ${ }^{33,34}$

\section{EXPERIMENTAL SECTION}

2.1. Materials. 9-Fluorenylmethoxycarbonyl (Fmoc) and tert-butoxycarbonyl (Boc) protected L-amino acids, lauric acid, Rink amide MBHA resin, and uronium hexafluorophosphate (HBTU) were purchased from NovaBiochem. N,N-Diisopropylethylamine (DIEA), dichloromethane (DCM), dimethylformamide (DMF), trifluoroacetic acid (TFA), fluorescein isothiocyanate isomer I (FITC), and all other chemicals used in peptide synthesis and material characterization were purchased from Merck, Fisher, Alfa Aesar, and Sigma-Aldrich. Live/Dead BacLight bacterial viability kit L-7012 was purchased from Life Technologies. Luria-Bertani bacterial culture medium was purchased from Merck, and LB broth with agar was purchased from Sigma. Calcein-AM and other cell culture materials were purchased from Invitrogen. Other chemicals and materials were purchased from either Sigma-Aldrich or Thermo Scientific. All chemicals and solvents used in this study were analytical grade.

2.2. Peptide Synthesis, Purification, and Characterization. Cationic antibacterial peptide amphiphile laurylVVAGKKKGRW-Am and cationic antibacterial soluble peptide Ac-KKKGRW-Am were synthesized on Rink amide MBHA resin $\left(0.46 \mathrm{mmol} \mathrm{g}^{-1}\right)$. Amino acid couplings were performed with 2:1.95:3 equiv of Fmoc-protected amino acid, HBTU, and $\mathrm{N}, \mathrm{N}$-diisopropylethylamine (DIEA), respectively, in dimethylformamide (DMF) for $5 \mathrm{~h}$. Twenty percent piperidine/DMF solution was used for $25 \mathrm{~min}$ to remove Fmoc protecting groups. A mixture of trifluoroacetic acid (TFA), triisopropylsilane (TIS), and water (95:2.5:2.5 ratio, respectively) was used for cleavage of the peptides from the resin for $2 \mathrm{~h}$. Excess TFA was removed by rotary evaporation. The remaining viscous peptide solution was treated with ice-cold diethyl ether at -20 ${ }^{\circ} \mathrm{C}$, and the resulting white pellet was freeze-dried. The peptides were identified and analyzed by reverse phase high performance liquid chromatography (HPLC) on an Agilent 6530 accurate-mass Q-TOF liquid chromatography/mass spectrometry (LC/MS) equipped with an Agilent 1200 HPLC. A Phenomenex Luna $3 \mu$ C8 100A $(50 \times 3.00 \mathrm{~mm})$ column was used as the stationary phase, and a water/ acetonitrile gradient with $0.1 \%$ formic acid was used as the mobile phase to identify the peptides. Peptides were purified by using a 1200 Agilent HPLC with a Zorbax 300SB C8 4.6 100 $\mathrm{mm}$ column and a water/acetonitrile $(0.1 \%$ TFA) gradient. Then, peptides were treated with $\mathrm{HCl}$ solution to exchange the trifluoroacetate salt.

2.3. Circular Dichroism (CD) Spectroscopy. CD spectra were recorded using a J-815 Jasco spectrophotometer at room temperature under a constant flow of nitrogen gas. Aqueous solutions $(125 \mu \mathrm{M})$ were diluted from $2 \mathrm{mM}$ stock solutions of peptides. $\mathrm{CD}$ spectra were obtained at $\mathrm{pH} 7.4$ within the data interval of 300 to $190 \mathrm{~nm}^{-1}$, with a bandwidth of $1.0 \mathrm{~nm}$, and a scanning speed of $500 \mathrm{~nm} \mathrm{~min}{ }^{-1}$. Scans were repeated three times and averaged. The results were converted to molar ellipticity per amino acid residue. To evaluate the effects of $\mathrm{pH}$ on secondary structure, the peptide amphiphile solution was prepared at $\mathrm{pH} 7.4$, and its $\mathrm{pH}$ was adjusted to $\mathrm{pH} 6.5$ from the fiber-making peptide amphiphile stock solution at $\mathrm{pH}$ 7.4.

2.4. Transmission Electron Microscopy. The peptide amphiphile solution was diluted from $2 \mathrm{mM}$ stock solution into $125 \mu \mathrm{M}$ at $\mathrm{pH} 7.4$ for sample preparation. Peptide nanofibers were placed on a transmission electron microscopy grid. After 7 min of incubation, uranyl acetate (2 wt \%) staining was 
performed for 1 min. A FEI Tecnai G2 F30 transmission electron microscope was used at $200 \mathrm{kV}$ for imaging. Soluble peptide solution was also diluted from $2 \mathrm{mM}$ stock solution into $1000 \mu \mathrm{M}$ for transmission electron microscopy characterization.

2.5. Antibacterial Activity Analysis. The antibacterial activity of both peptides and their minimum inhibitory concentrations (MICs) were assessed by Live/Dead analysis. A survival assay for both Escherichia coli and Bacillus subtilis bacteria was also used to compare the efficiencies of nanofiber structures and soluble peptides.

2.6. Minimum Inhibitory Concentration of Peptides. Escherichia coli (RSHM 888, National Type Culture Collection Laboratory, Ankara, Turkey) $)^{35,36}$ was used as a model system for Gram-negative bacteria, while Bacillus subtilis (ATCC 6633) was used as a model system for Gram-positive bacteria. Bacteria were cultured at $37^{\circ} \mathrm{C}$ in a shaking incubator at $200 \mathrm{rpm}$ for 14 $\mathrm{h}$ to achieve mid logarithmic growth phase. Luria-Bertani (LB) culture medium was used for bacterial growth, and broth dilution was performed after bacteria reached mid logarithmic growth phase. Both bacteria were diluted to $5 \times 10^{6} \mathrm{CFU} \mathrm{mL} \mathrm{m}^{-1}$ using fresh LB for minimum inhibitory concentration experiments. Bacterial CFU numbers were checked by both broth dilution and agar plate colony counting. $\mathrm{OD}_{600}=0.1$, as measured by M5 microplate reader (Molecular Devices), was accepted to be $10^{7}-10^{8} \mathrm{CFU} \mathrm{mL}^{-1}$ of bacteria as per McFarland Standard No. 1, and $5 \times 10^{5} \mathrm{CFU} \mathrm{mL}^{-1}$ of bacteria were used in minimum inhibitory concentration experiments.

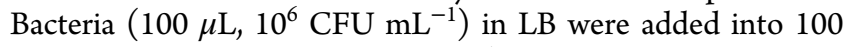
$\mu \mathrm{L}$ of peptide solution in $1 \times$ PBS (peptides were prepared in 96-well plate $1 \mathrm{~h}$ prior to addition). After incubating for $18 \mathrm{~h}$ in a shaking incubator at $37{ }^{\circ} \mathrm{C}, 20 \mu \mathrm{L}$ from each sample was seeded onto agar plates. Minimum inhibitory concentrations were measured as the lowest peptide concentration that inhibits bacterial growth. Bacterial cells in $100 \mu \mathrm{L}$ of $\mathrm{LB}$ and $100 \mu \mathrm{L}$ of $1 \times$ PBS mixture without peptides were used as positive control. For each concentration of peptides, three replicates were used.

2.7. Live/Dead Assay for Bacteria. A bacterial viability kit, containing SYTO9 for staining living bacterial cells and propidium iodide for staining dead bacterial cells, was used to evaluate bacterial cell viability in the presence of bioactive peptides. Six micromolar SYTO9 and $30 \mu \mathrm{M}$ propidium iodide were mixed in $1 \times$ PBS solution and used to fix previously prepared bacteria-peptide mixtures for $15 \mathrm{~min}$ in dark at room temperature. Five microliters of samples from each group were visualized with a Zeiss LSM 510 laser scanning confocal microscope. Excitation/emission values of the dyes are SYTO9, 480/500 nm, and propidium iodide, 490/635 nm.

2.8. Time-Kill Assay. Time-kill assay was performed with both peptide nanofiber- and soluble peptide-treated bacteria at each peptide's minimum inhibitory concentration. Ten microliters of samples were taken at 1,6 , and $24 \mathrm{~h}$ and incubated at $37{ }^{\circ} \mathrm{C}$ on agar plates. Number of bacteria prior to peptide addition was used for calculating \% survival rate.

2.9. Biocompatibility of Peptides for Mammalian Cells. Human umbilical vein endothelial cell (HUVEC) line was used in order to check the cytotoxicity of the peptides by Live/Dead assay (Invitrogen). HUVECs were donated by Yeditepe University, Istanbul, Turkey. Peptide solutions (100 $\mu \mathrm{L})$ in $1 \times$ PBS were mixed with 5000 cells/well in 96-well plates. After $24 \mathrm{~h}$ of incubation, the medium was discarded and wells were washed with $1 \times$ PBS. Then, wells were incubated with $2 \mu \mathrm{M}$ calcein-AM and $2 \mu \mathrm{M}$ EthD-1 in PBS for $30 \mathrm{~min}$ at room temperature. Three random images were taken for every well under a Zeiss, Axio Scope A1 fluorescence microscope at $10 \times$ magnification. ImageJ software was used for counting.

2.10. Visualization of Peptide Nanofibers by Confocal Microscopy. The peptide amphiphile stock solution was prepared at $2 \mathrm{mM}$. After $1 \mathrm{~h}$ of incubation at room temperature, FITC tagged peptide amphiphiles were mixed at a 5\% ratio into the antibacterial peptide amphiphile solution ${ }^{37-39}$ as we used previously. ${ }^{40}$ Bacteria were incubated with the peptide solution for $30 \mathrm{~min}$ at $37^{\circ} \mathrm{C}$ in a shaker incubator. Following peptide exposure, $5 \mu \mathrm{L}$ of samples were transferred between glass coverslips for imaging under a Zeiss LSM 510 laser scanning confocal microscope. FITC configurations were $488 \mathrm{~nm}$ excitation laser/505-530 nm emission filter.

2.11. Analyses of Morphological Changes of Bacteria by Scanning Electron Microscopy Imaging. A FEI Quanta 200 FEG scanning electron microscope with an ETD detector was used in order to visualize the morphological changes caused by both soluble peptides and peptide nanofibers on bacterial membranes. Bacterial cells were fixed with $2.5 \%$ glutaraldehyde in PBS for $1 \mathrm{~h}$. Samples were then postfixed with $1 \%$ osmium tetroxide for $1 \mathrm{~h}$ and dehydrated in a series of $20 \%, 40 \%, 60 \%, 80 \%$, and $100 \% \mathrm{EtOH}$ for 2 min per step. After the final $100 \% \mathrm{EtOH}$ step, the samples were kept in fresh $100 \%$ $\mathrm{EtOH}$ for at least $1 \mathrm{~h}$.

2.12. Analysis of Morphological Changes of Bacteria by Atomic Force Microscopy Imaging in Aqueous Environment. Mica surfaces were coated with gelatin in order to immobilize living bacteria for acquiring AFM images in liquid. $^{41}$ All AFM imaging experiments were performed in aqueous environment. Bacterial culture $(150-200 \mu \mathrm{L})$ was first dropped on a cleaved coated mica surface and waited 5-10 min. Then, equal volume of peptide amphiphile solution or soluble peptide solution was added onto the bacterial cells. A total of $300-400 \mu \mathrm{L}$ of sample volume were imaged using an Asylum Research MFP-3D atomic force microscope under tapping mode. Soft silicon nitride tips with nominal spring constants of $0.05 \mathrm{~N} / \mathrm{m}$ were used for imaging. Atomic force micrographs were taken at a resolution of $512 \times 512$ pixels or $1024 \times 1024$ pixels.

2.13. Statistical Analysis. Results are expressed as mean \pm standard deviation or with $95 \%$ confidence intervals. One-way analysis of variance (ANOVA) with Tukey's Multiple Comparison Test (GraphPad Prism v5) was used to compare values between the experimental groups (Figure $3 \mathrm{~d}$ ). $p \leq 0.05$ was considered as statistically significant. In Graphpad Prism, D’Agostino-Pearson, Shapiro-Wilk, and Kolmogorov-Smirnov normality tests were used to test if the values are from a Gaussian distribution.

\section{RESULTS}

The self-assembling peptide lauryl-VVAGKKKGRW-Am and soluble peptide Ac-KKKGRW-Am were synthesized using Fmoc solid phase peptide synthesis method to compare the antibacterial activity of soluble and nanofibrous peptides on Gram-positive B. subtilis and Gram-negative E. coli. This sequence was chosen due to previous results in the antimicrobial effect of the arginine-tryptophan couple ${ }^{42,43}$ and our results on multiple lysine-carrying sequences for antibacterial activity (Figure S4). In Ac-KKKGRW-Am peptide, the free alpha amine is acetylated to prevent the inclusion of an additional charged group in the sequence and limit the interaction of the peptide with other molecules. Both peptides 
a)

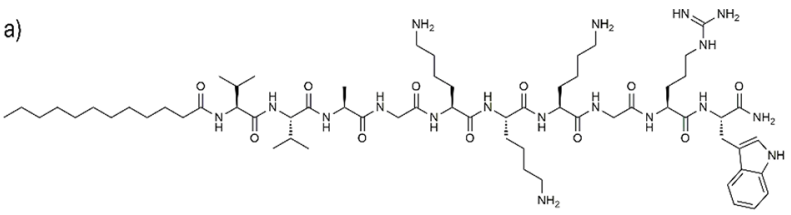

b)

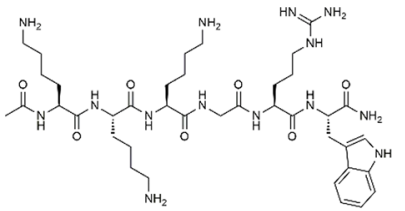

c)

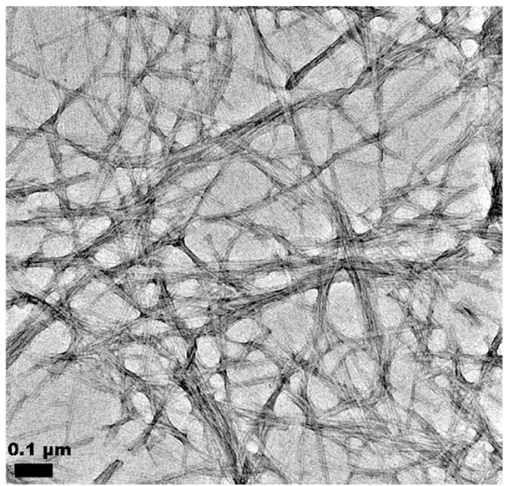

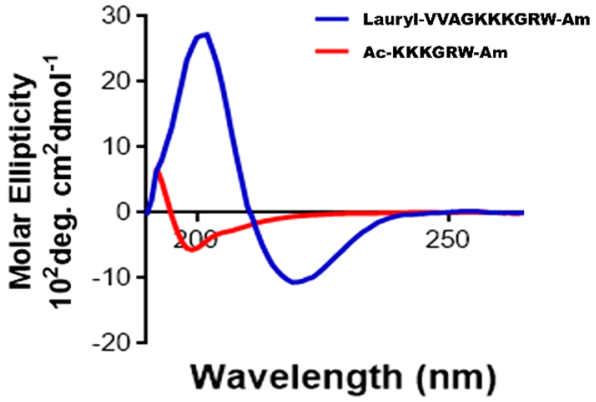

Figure 1. Chemical representation of the peptide amphiphile lauryl-VVAGKKKGRW-Am (a) and single peptide Ac-KKKGRW-Am (b). Transmission electron microscopy image of peptide amphiphiles (c) following their self-assembly into supramolecular nanofibers, in contrast to soluble peptides showing no nanofiber formation (Figure S2). (d) CD spectra of both peptides.

a)

\begin{tabular}{l|l|c|c}
\hline & \multicolumn{1}{|c|}{ Sequence } & $\begin{array}{c}\text { MIC } \\
\text { E.coli }(\mu \mathrm{M})\end{array}$ & $\begin{array}{c}\text { MIC } \\
\text { B.subtilis }(\mu \mathrm{M})\end{array}$ \\
\hline Peptide Nanofiber & Lauryl-WVAGKKKGRW-Am & 125 & 125 \\
Soluble Peptide & Ac-KKKGRW-Am & 1000 & 1000 \\
\hline
\end{tabular}

MIC : Minimum Inhibitory Concentration

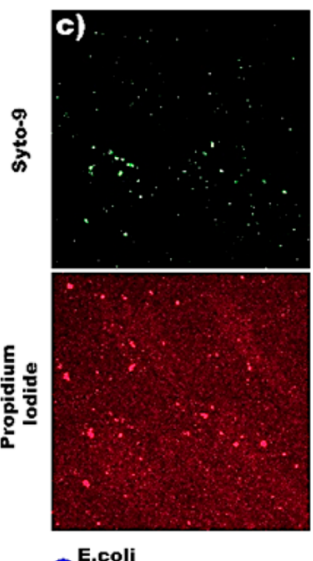

E.coli Mic fiber (125 $\mu \mathrm{M})$

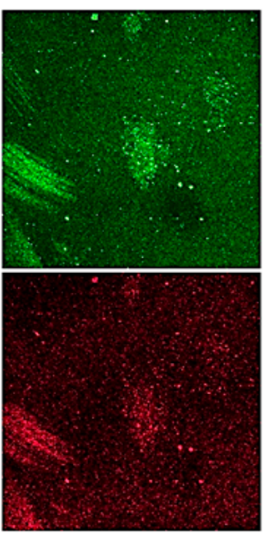

E.coli

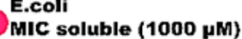

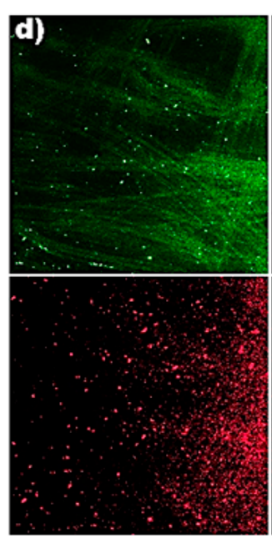
B.subtilis
MIC fiber (125 $\mu \mathrm{M})$ b)
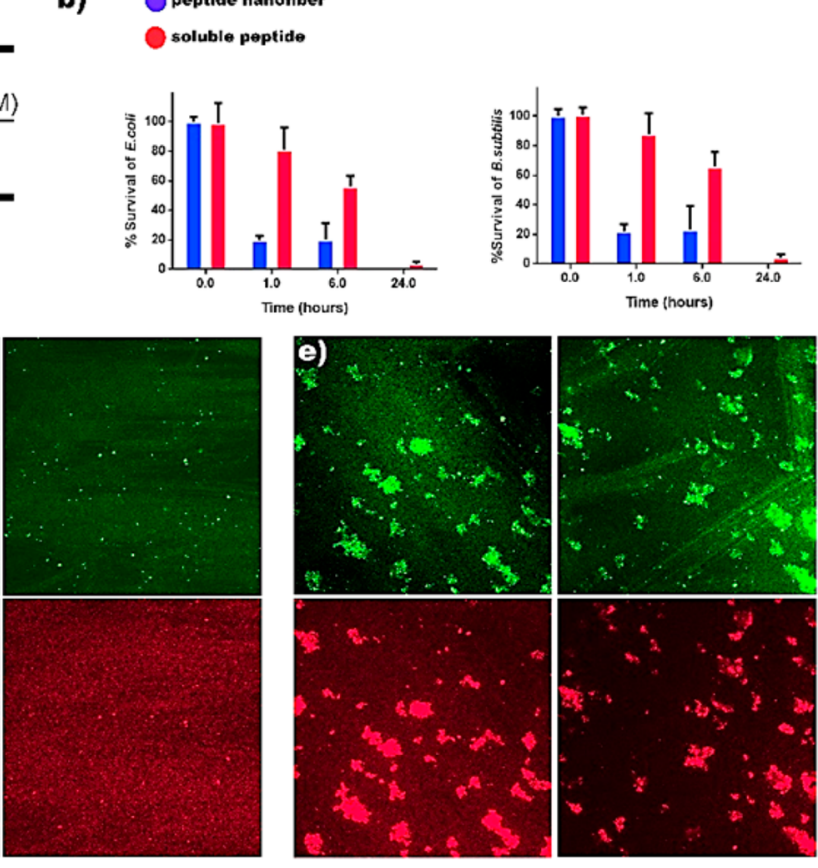

B.subtilis
MIC soluble (1000 $\mu \mathrm{M})$

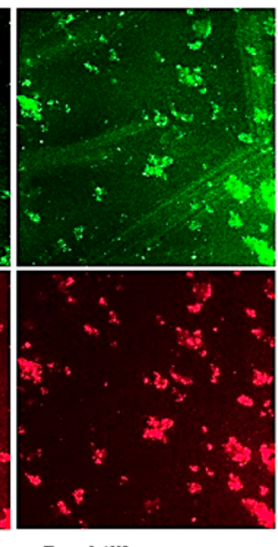

B.subtilis

Figure 2. Minimum inhibitory concentrations of both peptides (a). Time-kill assay of bacteria by peptides (b). Error bars represent standard deviation, $n=3$. E. coli and B. subtilis cells stained with Baclight live/dead bacterial viability kit (c-e).

(Figure 1a,b) exhibit a potential antimicrobial sequence through their lysine, arginine, and tryptophan residues; however, the soluble peptide (Figure 1b) lacks the hydrophobic alkyl tail or the $\beta$-sheet forming VVA sequence. The peptides were purified and characterized by LC/MS (Figure S1a,b). Transmission electron microscopy was also used to visualize the general morphology of both peptides. Peptide amphiphiles were observed in a nanofiber morphology (Figure 1c), while aggregate formation was not observed for the soluble peptide (Figure S2).
In $\mathrm{CD}$ measurements, the peptide amphiphile molecules exhibited a local maximum peak around $200 \mathrm{~nm}$ and a local minimum peak around $220 \mathrm{~nm}$ and demonstrated a predominantly $\beta$-sheet structure, whereas the soluble peptide exhibited a local minimum peak around $195 \mathrm{~nm}$ and demonstrated a predominantly random-coil structure (Figure 1d). $\mathrm{CD}$ spectra were also acquired at different $\mathrm{pH}$ values to determine the $\mathrm{pH}$ at which the nanofiber morphology is disrupted, and the $\beta$-sheet morphology was found to be present at $\mathrm{pH} 7.4$ but not $\mathrm{pH} 6.5$ (Figure S6). For this experiment, the 
Peptide Nanofiber Treated

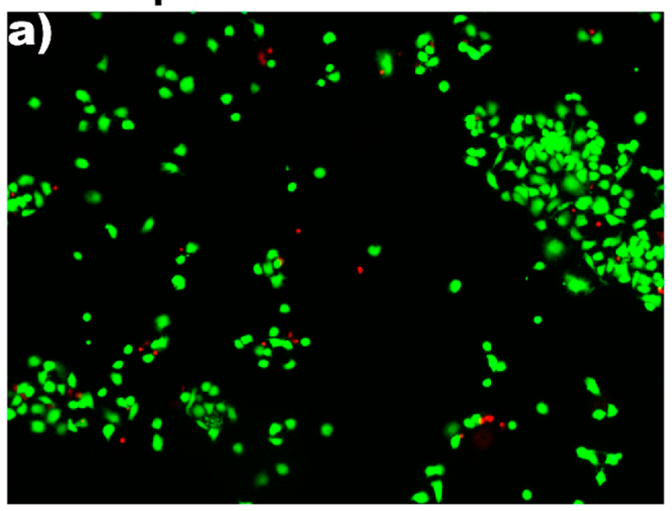

TCP

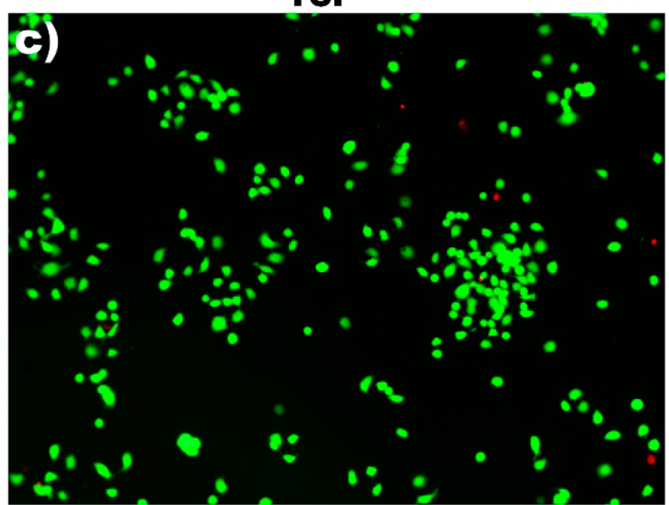

Soluble Peptide Treated

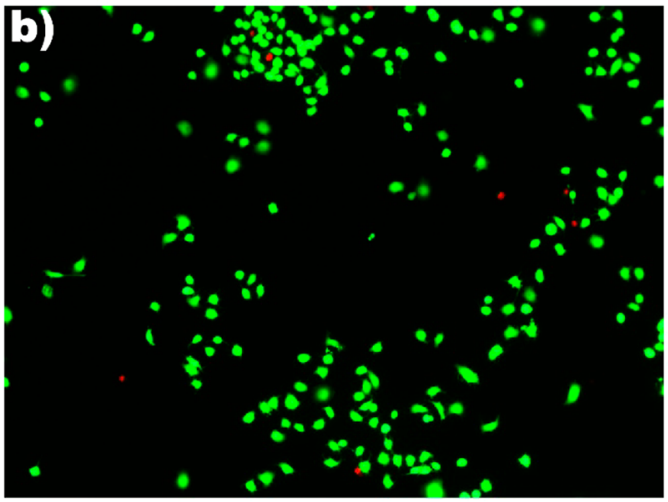

d)

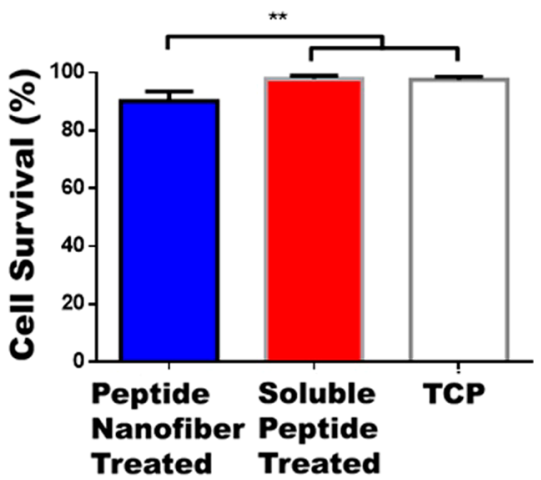

Figure 3. Fluorescent images of HUVECs with peptide nanofibers (a), with soluble peptides (b), and without any peptide treatment (tissue culture plate control) (c) after $24 \mathrm{~h}$ of incubation using live/dead assay. Cytotoxicity of peptides on HUVECs (d).

$\mathrm{pH} 6.5$ sample was prepared from the fiber-making stock solution at $\mathrm{pH} 7.4$.

Minimum inhibitory concentrations of both peptides were determined against both Gram-positive and Gram-negative bacteria by broth dilution and colony forming unit (CFU) counting methods. Briefly, peptides were serially diluted in $1 \times$ PBS solutions and mixed with equal volume of bacteria in fresh LB prior to counting assays. Inhibitory concentrations of peptides against Gram-negative (E. coli) and Gram-positive (B. subtilis) bacteria are shown in Figure 2a. Half serial dilutions of peptides were prepared from $2 \mathrm{mM}$ stock solutions, and the lowest dilution that was sufficient to kill all bacteria in agar plates was considered to be the minimum inhibitory concentration. As shown in Figure 2a, the antibacterial peptide nanofibers were 4-8 times more effective than their antibacterial soluble peptide counterparts in terms of concentration values. The nanofiber form of the antibacterial peptides was therefore found to be much more effective for bactericidal activity compared to presentation of otherwise identical sequences in solution.

To compare the rate of antibacterial action, a time-kill assay was performed by taking $10 \mu \mathrm{L}$ from both peptide nanofibertreated and soluble peptide-treated groups at 1, 6, and $24 \mathrm{~h}$ time points. Both peptides were used at their minimum inhibitory concentrations for this experiment. Incubation and CFU counting showed that, while soluble peptide killed around $20 \%$ of bacteria, peptide nanofibers killed around $80 \%$ after $1 \mathrm{~h}$ of incubation (Figure 2b).

BacLight bacterial live/dead kit, containing the nucleic acid stains Syto-9 and PI, was used to visualize bacterial survival after $1 \mathrm{~h}$ of incubation. ${ }^{44}$ After $1 \mathrm{~h}$ of bacterial incubation with peptide nanofibers or soluble peptides, both cationic peptide systems were observed to kill bacteria in their effective concentrations (as determined by minimum inhibitory concentration results) (Figure $2 \mathrm{c}, \mathrm{d}$ ). Staining also confirmed the difference between the live/dead ratios of peptide nanofiber-treated and soluble peptide-treated groups with respect to bactericidal activity.

Biocompatibility of both peptides with mammalian cells was investigated using HUVECs. These cells are frequently used as models for endothelial cells, which are the first cells encountered by antimicrobial agents that are administered intravenously. ${ }^{45}$ Even though the survival of peptide nanofibertreated HUVECs was significantly lower than that of soluble peptide-treated cells, biocompatibility of the peptide nanofiber was within an acceptable range compared to tissue culture plate control (Figure 3).

Visualization of peptide nanofibers on bacteria was performed by confocal microscopy. A mixture of fluorescently labeled peptide amphiphile molecules (FITC-PA) and nonfluorescent antibacterial peptide amphiphile molecules created peptide nanofibers that could be detected on both Grampositive and -negative bacteria after $10 \mathrm{~min}$ of incubation (Figure S5). The images (Figure $4 a-d$ ) show fluorescence spreading throughout the bacterial cells, which suggests the internalization of FITC labeled peptides into the cytoplasm of both bacteria. ${ }^{46}$ Time-lapsed imaging was also performed using peptide nanofibers (5\% FITC) (Figure $4 \mathrm{e})$. The first image (0 s) was taken $40 \mathrm{~s}$ after the addition of fluorescently labeled nanofibers. These results show the rapid binding of peptide nanofibers to bacterial membranes. 


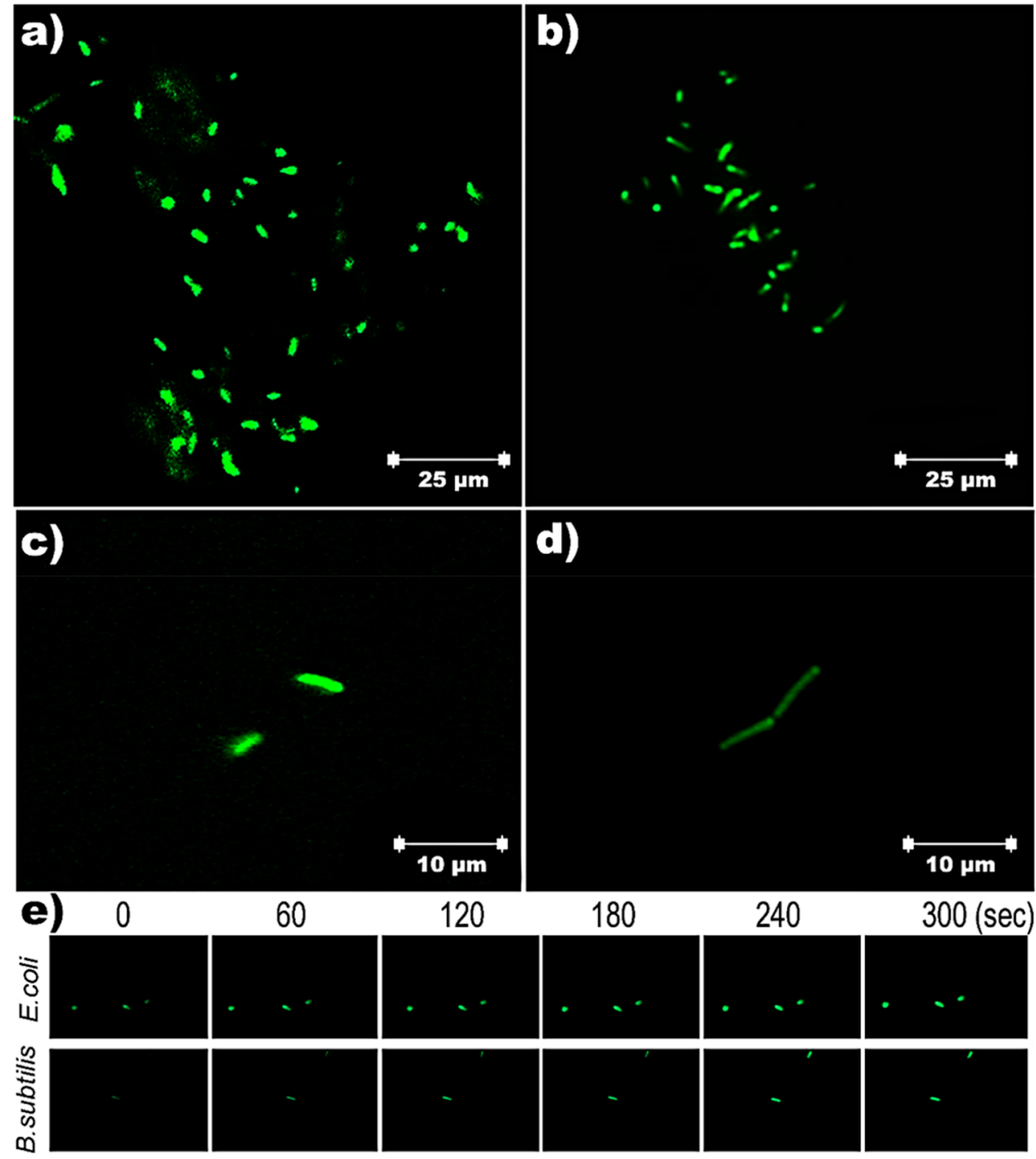

Figure 4. Confocal microscopy images of peptide nanofibers and E. coli RSHM 888 (a,c) and B. subtilis ATCC 6633 (b,d). Snapshots show fast membrane binding of nanofibers (e).

Antibacterial peptide nanofiber- and soluble peptide-treated bacteria were visualized by both atomic force microscopy and scanning electron microscopy in order to determine the morphological effects of peptide treatment on bacterial cells. In the self-assembling peptide-treated group, peptide nanofibers were observed to be distributed evenly across the mica surface (Figure 5a,b), which is potentially beneficial for antimicrobial applications of the peptide system on catheters and other biofilm-prone surfaces, as these nanofibrous structures exhibited a dense network formation that may protect a large area against bacterial entry. However, consistent with TEM results, no nanofibers were observed in the soluble peptidetreated group (Figure 5c). After encountering the bacterial membrane, peptide nanofibers are expected to penetrate inside the membrane structure through hydrophobic interactions. After $1 \mathrm{~h}$ of incubation of peptides with bacteria, distinct circular areas around clustered bacteria can be observed (Figure 5a), and phase differences in these areas suggest that bacteria were losing cytoplasmic fluid to the environment, which is consistent with our observations. In addition, sequential measurement of nanofiber-treated samples showed increased nanofiber length (Figure 5d). Higher-magnification atomic force microscopy images of bacteria (Figure 5e) showed disruptions in bacterial membranes, especially for nanofibertreated groups in phase images. Both groups were treated with minimum inhibitory concentrations $(125 \mu \mathrm{M}$ for nanofiber, 1 $\mathrm{mM}$ for soluble peptide), and atomic force microscopy images were taken after $10 \mathrm{~min}$ of interaction in water.

E. coli cells were also fixed with $2.5 \%$ glutaraldehyde for 60 min for the scanning electron microscopy characterization of cell-nanofiber interactions. In both scanning electron microscopy and atomic force microscopy results, nanofiber treatment was found to be associated with strong disruption of bacterial membranes (Figure 5). Destabilized, disrupted membranes and shrunken bacterial morphologies exhibiting nonstandard behavior were also observed under peptide nanofiber treatment. In addition, clear membrane ruptures (Figure 5f) can be observed for the soluble peptide-treated group.

\section{DISCUSSION}

There are several concepts for the mode-of-action of antimicrobial peptides. ${ }^{47}$ The self-assembly method can be utilized to develop multivalent peptide systems for antimicrobial activity by disrupting bacterial membrane. ${ }^{48}$ Here, we 
a)

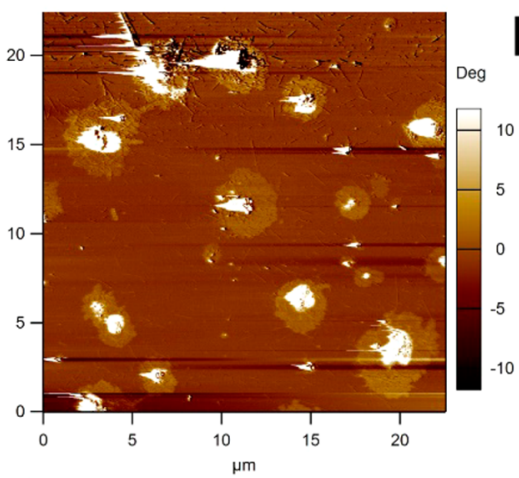

d)

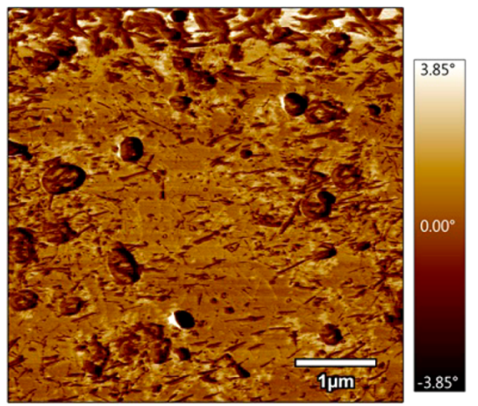

b)
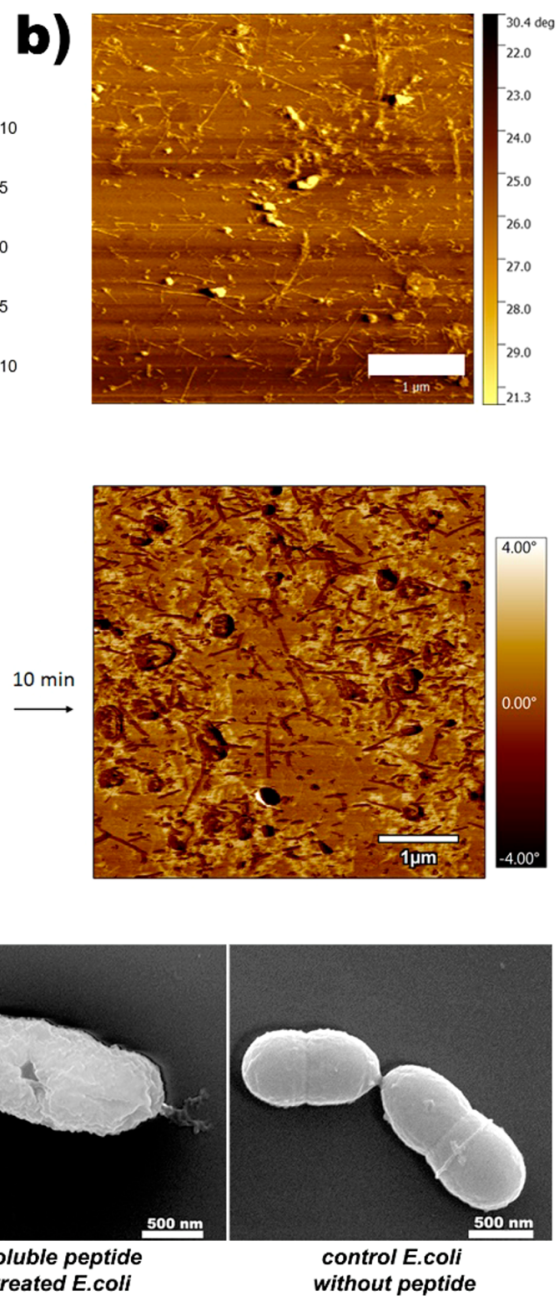

without peptid

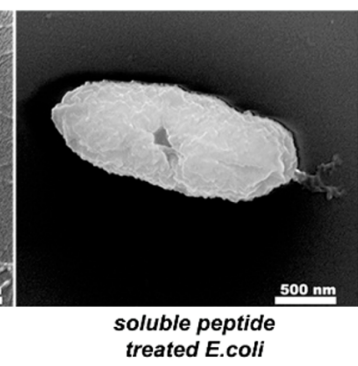

c)

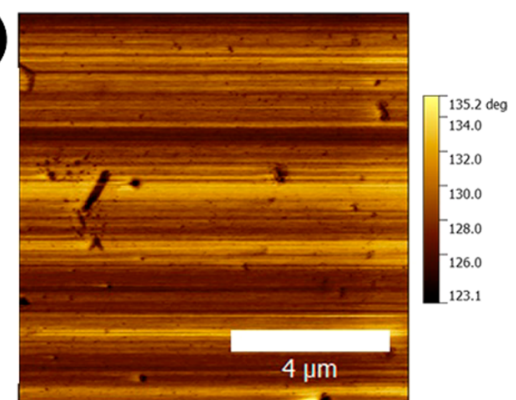

e)

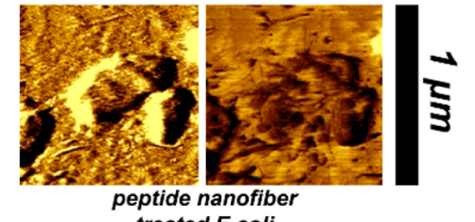

peptide nanofiber
treated E.coli

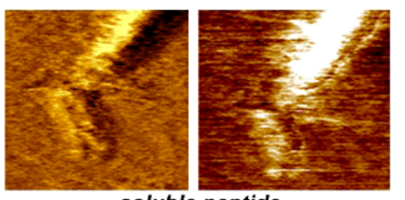

soluble peptide

treated E.coli

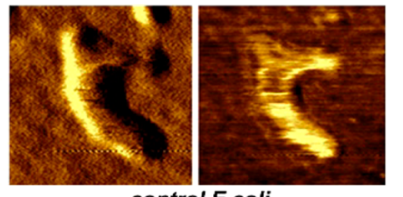

control E.coli

without peptide

Figure 5. Cell membrane disruption induced by antibacterial peptides. Atomic force microscopy images were obtained in water under tapping mode. AFM phase image of nanofiber-treated B. subtilis cells (a) following $1 \mathrm{~h}$ of incubation, phase image of nanofiber-treated E. coli cells (b), phase image of soluble peptide-treated E. coli cells (c), flattened phase images of peptide nanofiber-treated E. coli cells (d), higher-magnification images (e), and scanning electron micrographs of E. coli cells in contact with peptide nanofibers and soluble peptides (f). Scale bar: (c) $1 \mu \mathrm{m},(\mathrm{d}) 4 \mu \mathrm{m}$, and (f) 500 nm.

exploited soluble Ac-KKKGRW-Am peptide, which shows antibacterial activity in high doses. The self-assembly of peptide amphiphiles is known to provide supramolecular amphipathicity to peptide networks and potentially create a charge-density in the periphery of the nanofibers, which is a driving force for improved antibacterial activity. Xu et al. previously reported that $\mathrm{D}$-amino acid substitution in peptides can improve antimicrobial activity despite reducing nanofiber integrity. ${ }^{49}$ Therefore, the self-assembly might produce a greater antimicrobial effect by simply accumulating the individual peptide units and then promoting membrane disruption by disassembled monomers when a local threshold concentration is obtained.

Increasing peptide nanofiber concentration was observed to be associated with bacterial cell accumulations under live/dead analysis (Figure 2e). This might suggest that, unlike soluble peptide molecules, the mesh-like network produced by the selfassembling PA system may also allow the filtering of bacterial cells from liquid environments through membrane-peptide interactions.

Mammalian cells are expected to be resistant to the proposed charge interaction of the peptide system, as their membranes exhibit a zwitterionic nature and contain phosphatidylcholine, sphingomyelin, and phosphatidylserine phospholipids. Nevertheless, AMPs with strongly hydrophobic character can interact with phosphatidylcholine found in the mammalian cellular membrane and affect membrane integrity. ${ }^{50}$ Therefore, nanofiber aggregates with strong hydrophobicity slightly affected the mammalian cells.

Atomic force microscopy and scanning electron microscopy results demonstrated that membrane destabilization is the mode of action for both peptides. Both peptides potentially targeted bacterial membranes. This specific targeting effect may derive from the cationic amino acids in the peptide sequences and the penetrating ability of the hydrophobic tryptophan residue into bacterial membranes, which have previously been suggested in the literature. Consistent with the survival data, atomic force microscopy and scanning electron microscopy results suggest faster bacterial membrane destabilization for peptide nanofiber-treated groups compared to soluble peptidetreated groups for both Gram-positive and Gram-negative bacterial samples. 


\section{CONCLUSION}

While research in antimicrobial peptides has been advancing rapidly, $\beta$-sheet containing AMP studies are still rare. This work focuses on the multivalent presentation of antimicrobial peptides on peptide nanofibers and provides additional information on the dynamics of $\beta$-sheet forming AMPs. A short-sequenced peptide amphiphile molecule was used against E. coli and B. subtilis. Short sequence peptides with lower molecular masses are less immunogenic, and this could be beneficial for the practical applications of AMPs against pathogens. Peptide amphiphile molecules create positively charged clusters at the nanofiber periphery, which may increase their effective molarity compared to soluble peptide molecules. $^{51}$ We observed antibacterial effects of peptide amphiphiles against both Gram-positive and Gram-negative bacteria. Since both bacteria were affected similarly, the sequence is considered to have broad-spectrum activity against bacteria. While the cationic interactions cause destabilization of bacterial membranes, the higher hydrophobicity of the peptide network system is detrimental to mammalian cell membranes due to peptide-zwitterionic phospholipid interactions. However, the antibacterial activity of the peptide system was improved eight times under the nanofiber configuration, while the associated cytotoxicity was still not significant. FITC-tagged localization results showed the fast accumulation of peptide nanofibers on bacteria, which is an important parameter due to the necessity of cell-peptide associations for membrane disruption and penetration. Peptide nanofibers were also observed to be directly associated with bacteria. The nanofiber network of cationic AMPs was observed to attach to the bacterial membranes and actively disrupt them. While it is uncertain whether the soluble AMPs also function in a similar way, they have also facilitated the destabilization of bacterial membranes. Overall, our findings support the improvement of antibacterial activity of short cationic peptides when presented in the nanofiber form. In addition, $\beta$-sheet structure and molecular interactions of peptide amphiphiles create a more stable cationic AMP for use in therapeutic applications. Furthermore, length-dependent effects of the RW combination have been previously shown in the literature. ${ }^{42}$ Consequently, the cationic sequences described in the present study can be repeated to increase the positive charge and modulate the balance of hydrophobic and hydrophilic residues to promote antibacterial activity and decrease toxicity to mammalian cells in further studies.

\section{ASSOCIATED CONTENT}

\section{S Supporting Information}

The Supporting Information is available free of charge on the ACS Publications website at DOI: 10.1021/acs.molpharmaceut.7b00434.

Detailed characterization of the materials and experimental details (PDF)

\section{AUTHOR INFORMATION}

\section{Corresponding Authors}

*E-mail: mguler@uchicago.edu (M.O.G.).

*E-mail: atekinay@bilkent.edu.tr (A.B.T.).

ORCID $\odot$

Ayse B. Tekinay: 0000-0002-4453-814X

Mustafa O. Guler: 0000-0003-1168-202X

\section{Notes}

The authors declare no competing financial interest.

\section{ACKNOWLEDGMENTS}

We thank Ms. F. B. Dikecoglu for atomic force microscopy concentration analysis and Dr. A. D. Ozkan for valuable discussions. We also would like to thank TEM specialist Mr. M. Guler for transmission electron microscopy analysis. This work was partially supported by TUBA and TUBITAK.

\section{REFERENCES}

(1) Khachatourians, G. G. Agricultural Use of Antibiotics and the Evolution and Transfer of Antibiotic-Resistant Bacteria. CMAJ. 1998, 159 (9), 1129-1136.

(2) Smith, D. L.; Harris, A. D.; Johnson, J. A.; Silbergeld, E. K.; Morris, J. G. Animal Antibiotic Use Has an Early but Important Impact on the Emergence of Antibiotic Resistance in Human Commensal Bacteria. Proc. Natl. Acad. Sci. U. S. A. 2002, 99 (9), 6434-6439.

(3) Gullberg, E.; Cao, S.; Berg, O. G.; Ilbäck, C.; Sandegren, L.; Hughes, D.; Andersson, D. I. Selection of Resistant Bacteria at Very Low Antibiotic Concentrations. PLoS Pathog. 2011, 7 (7), e1002158.

(4) Davies, J.; Davies, D. Origins and Evolution of Antibiotic Resistance. Microbiol. Mol. Biol. Rev. 2010, 74 (3), 417-433.

(5) Conly, J.; Johnston, B. Where Are All the New Antibiotics? The New Antibiotic Paradox. Can. J. Infect. Dis. Med. Microbiol. $=J$. Can. des Mal. Infect. la Microbiol. medicale 2005, 16 (3), 159-160.

(6) Silver, L. L. Challenges of Antibacterial Discovery. Clin. Microbiol. Rev. 2011, 24 (1), 71-109.

(7) Perfeito, L.; Fernandes, L.; Mota, C.; Gordo, I. Adaptive Mutations in Bacteria: High Rate and Small Effects. Science (Washington, DC, U. S.) 2007, 317 (5839), 813-815.

(8) Tenaillon, O.; Denamur, E.; Matic, I. Evolutionary Significance of Stress-Induced Mutagenesis in Bacteria. Trends Microbiol. 2004, 12 (6), 264-270.

(9) Hibbing, M. E.; Fuqua, C.; Parsek, M. R.; Peterson, S. B. Bacterial Competition: Surviving and Thriving in the Microbial Jungle. Nat. Rev. Microbiol. 2010, 8 (1), 15-25.

(10) Martinez, J. L. Antibiotics and Antibiotic Resistance Genes in Natural Environments. Science (Washington, DC, U. S.) 2008, 321 (5887), 365-367.

(11) Zasloff, M. Antimicrobial Peptides of Multicellular Organisms. Nature 2002, 415 (6870), 389-395.

(12) Findlay, B.; Zhanel, G. G.; Schweizer, F. Cationic Amphiphiles, a New Generation of Antimicrobials Inspired by the Natural Antimicrobial Peptide Scaffold. Antimicrob. Agents Chemother. 2010, 54 (10), 4049-4058.

(13) Shai, Y. Mechanism of the Binding, Insertion and Destabilization of Phospholipid Bilayer Membranes by $\alpha$-Helical Antimicrobial and Cell Non-Selective Membrane-Lytic Peptides. Biochim. Biophys. Acta, Biomembr. 1999, 1462 (1-2), 55-70.

(14) Epand, R. M.; Vogel, H. J. Diversity of Antimicrobial Peptides and Their Mechanisms of Action. Biochim. Biophys. Acta, Biomembr. 1999, 1462 (1-2), 11-28.

(15) Wade, D.; Boman, A.; Wahlin, B.; Drain, C. M.; Andreu, D.; Boman, H. G.; Merrifield, R. B. All-D Amino Acid-Containing Channel-Forming Antibiotic Peptides. Proc. Natl. Acad. Sci. U. S. A. 1990, 87 (12), 4761-4765.

(16) Melo, M. N.; Ferre, R.; Castanho, M. A. R. B. Antimicrobial Peptides: Linking Partition, Activity and High Membrane-Bound Concentrations. Nat. Rev. Microbiol. 2009, 7 (3), 245-250.

(17) Lai, Y.; Gallo, R. L. AMPed up Immunity: How Antimicrobial Peptides Have Multiple Roles in Immune Defense. Trends Immunol. 2009, 30 (3), 131-141.

(18) Craik, D. J.; Fairlie, D. P.; Liras, S.; Price, D. The Future of Peptide-Based Drugs. Chem. Biol. Drug Des. 2013, 81 (1), 136-147.

(19) Costa, F.; Carvalho, I. F.; Montelaro, R. C.; Gomes, P.; Martins, M. C. L. Covalent Immobilization of Antimicrobial Peptides (AMPs) onto Biomaterial Surfaces. Acta Biomater. 2011, 7 (4), 1431-1440. 
(20) Zhao, Y.; Imura, T.; Leman, L. J.; Curtiss, L. K.; Maryanoff, B. E.; Ghadiri, M. R. Mimicry of High-Density Lipoprotein: Functional Peptide-Lipid Nanoparticles Based on Multivalent Peptide Constructs. J. Am. Chem. Soc. 2013, 135 (36), 13414-13424.

(21) Montet, X.; Funovics, M.; Montet-Abou, K.; Weissleder, R.; Josephson, L. Multivalent Effects of RGD Peptides Obtained by Nanoparticle Display. J. Med. Chem. 2006, 49 (20), 6087-6093.

(22) Castelletto, V.; de Santis, E.; Alkassem, H.; Lamarre, B.; Noble, J. E.; Ray, S.; Bella, A.; Burns, J. R.; Hoogenboom, B. W.; Ryadnov, M. G. Structurally Plastic Peptide Capsules for Synthetic Antimicrobial Viruses. Chem. Sci. 2016, 7 (3), 1707-1711.

(23) Whitesides, G. M.; Grzybowski, B. Self-Assembly at All Scales. Science (Washington, DC, U. S.) 2002, 295 (5564), 2418-2421.

(24) Loo, Y.; Goktas, M.; Tekinay, A. B.; Guler, M. O.; Hauser, C. A. E.; Mitraki, A. Self-Assembled Proteins and Peptides as Scaffolds for Tissue Regeneration. Adv. Healthcare Mater. 2015, 4 (16), 2557-2586.

(25) Woolfson, D. N.; Ryadnov, M. G. Peptide-Based Fibrous Biomaterials: Some Things Old, New and Borrowed. Curr. Opin. Chem. Biol. 2006, 10 (6), 559-567.

(26) Dieckmann, G. R.; Dalton, A. B.; Johnson, P. A.; Razal, J.; Chen, J.; Giordano, G. M.; Muñoz, E.; Musselman, I. H.; Baughman, R. H.; Draper, R. K. Controlled Assembly of Carbon Nanotubes by Designed Amphiphilic Peptide Helices. J. Am. Chem. Soc. 2003, 125 (7), 17701777.

(27) Faruqui, N.; Bella, A.; Ravi, J.; Ray, S.; Lamarre, B.; Ryadnov, M. G. Differentially Instructive Extracellular Protein Micro-Nets. J. Am. Chem. Soc. 2014, 136 (22), 7889-7898.

(28) Giano, M. C.; Ibrahim, Z.; Medina, S. H.; Sarhane, K. A.; Christensen, J. M.; Yamada, Y.; Brandacher, G.; Schneider, J. P. Injectable Bioadhesive Hydrogels with Innate Antibacterial Properties. Nat. Commun. 2014, 5, 1-9.

(29) Sinthuvanich, C.; Veiga, A. S.; Gupta, K.; Gaspar, D.; Blumenthal, R.; Schneider, J. P. Anticancer $\beta$-Hairpin Peptides: Membrane-Induced Folding Triggers Activity. J. Am. Chem. Soc. 2012, 134 (14), 6210-6217.

(30) Hartgerink, J. D.; Beniash, E.; Stupp, S. I. Self-Assembly and Mineralization of Peptide-Amphiphile Nanofibers. Science 2001, 294 (5547), 1684-1688.

(31) Bulut, S.; Erkal, T. S.; Toksoz, S.; Tekinay, A. B.; Tekinay, T.; Guler, M. O. Slow Release and Delivery of Antisense Oligonucleotide Drug by Self-Assembled Peptide Amphiphile Nanofibers. Biomacromolecules 2011, 12 (8), 3007-3014.

(32) Tansik, G.; Kilic, E.; Beter, M.; Demiralp, B.; Kiziltas Sendur, G.; Can, N.; Ozkan, H.; Ergul, E.; Guler, M. O.; Tekinay, A. B. A Glycosaminoglycan Mimetic Peptide Nanofiber Gel as an Osteoinductive Scaffold. Biomater. Sci. 2016, 4 (9), 1328-1339.

(33) Blazyk, J.; Wiegand, R.; Klein, J.; Hammer, J.; Epand, R. M.; Epand, R. F.; Maloy, W. L.; Kari, U. P. A Novel Linear Amphipathic $\beta$ Sheet Cationic Antimicrobial Peptide with Enhanced Selectivity for Bacterial Lipids. J. Biol. Chem. 2001, 276 (30), 27899-27906.

(34) Heller, W. T.; Waring, A. J.; Lehrer, R. I.; Harroun, T. A.; Weiss, T. M.; Yang, L.; Huang, H. W. Membrane Thinning Effect of the $\beta$ Sheet Antimicrobial Protegrin $\uparrow$. Biochemistry 2000, 39 (1), 139-145.

(35) Ozkan, A. D.; Han, D.; Umu, O. C. O.; Angun, P.; Senturk, B.; Yasa, O.; Tekinay, T. Screening and Selection of Novel Animal Probiotics Isolated from Bovine Chyme. Ann. Microbiol. 2013, 63 (4), $1291-1300$

(36) Kayaci, F.; Umu, O. C. O.; Tekinay, T.; Uyar, T. Antibacterial Electrospun Poly(lactic Acid) (PLA) Nanofibrous Webs Incorporating Triclosan/Cyclodextrin Inclusion Complexes. J. Agric. Food Chem. 2013, 61 (16), 3901-3908.

(37) Chow, L. W.; Bitton, R.; Webber, M. J.; Carvajal, D.; Shull, K. R.; Sharma, A. K.; Stupp, S. I. A Bioactive Self-Assembled Membrane to Promote Angiogenesis. Biomaterials 2011, 32 (6), 1574-1582.

(38) Zha, R. H.; Sur, S.; Stupp, S. I. Self-Assembly of Cytotoxic Peptide Amphiphiles into Supramolecular Membranes for Cancer Therapy. Adv. Healthcare Mater. 2013, 2 (1), 126-133.

(39) Sardan, M.; Yildirim, A.; Mumcuoglu, D.; Tekinay, A. B.; Guler, M. O. Noncovalent Functionalization of Mesoporous Silica Nano- particles with Amphiphilic Peptides. J. Mater. Chem. B 2014, 2 (15), 2168-2174.

(40) Hamsici, S.; Cinar, G.; Celebioglu, A.; Uyar, T.; Tekinay, A. B.; Guler, M. O. Bioactive peptide functionalized aligned cyclodextrin nanofibers for neurite outgrowth. J. Mater. Chem. B 2017, 5 (3), 517524.

(41) Allison, D. P.; Sullivan, C. J.; Mortensen, N. P.; Retterer, S. T.; Doktycz, M. Bacterial Immobilization for Imaging by Atomic Force Microscopy. J. Visualized Exp. 2011, No. 54, 2880.

(42) Liu, Z.; Brady, A.; Young, A.; Rasimick, B.; Chen, K.; Zhou, C.; Kallenbach, N. R. Length Effects in Antimicrobial Peptides of the (RW)n Series. Antimicrob. Agents Chemother. 2007, 51 (2), 597-603.

(43) Chan, D. I.; Prenner, E. J.; Vogel, H. J. Tryptophan- and Arginine-Rich Antimicrobial Peptides: Structures and Mechanisms of Action. Biochim. Biophys. Acta, Biomembr. 2006, 1758 (9), 1184-1202.

(44) Liu, S.; Tonggu, L.; Niu, L.; Gong, S.; Fan, B.; Wang, L.; Zhao, J.; Huang, C.; Pashley, D. H.; Tay, F. R. Antimicrobial Activity of a Quaternary Ammonium Methacryloxy Silicate-Containing Acrylic Resin: A Randomised Clinical Trial. Sci. Rep. 2016, 6 (1), 21882.

(45) Ho, M.-H.; Guo, Z.-M.; Chunga, J.; Goodwin, J. S.; Xie, H. Characterization of Innate Immune Responses of Human Endothelial Cells Induced by Porphyromonas Gingivalis and Their Derived Outer Membrane Vesicles. Front. Cell. Infect. Microbiol. 2016, 6, 139.

(46) Joshi, S.; Bisht, G. S.; Rawat, D. S.; Kumar, A.; Kumar, R.; Maiti, S.; Pasha, S. Interaction Studies of Novel Cell Selective Antimicrobial Peptides with Model Membranes and E. Coli ATCC 11775. Biochim. Biophys. Acta, Biomembr. 2010, 1798 (10), 1864-1875.

(47) Wimley, W. C.; Hristova, K. Antimicrobial Peptides: Successes, Challenges and Unanswered Questions. J. Membr. Biol. 2011, 239 (12), 27-34.

(48) Ravi, J.; Bella, A.; Correia, A. J. V.; Lamarre, B.; Ryadnov, M. G. Supramolecular Amphipathicity for Probing Antimicrobial Propensity of Host Defence Peptides. Phys. Chem. Chem. Phys. 2015, 17 (24), 15608-15614.

(49) Xu, D.; Jiang, L.; Singh, A.; Dustin, D.; Yang, M.; Liu, L.; Lund, R; Sellati, T. J.; Dong, H. Designed Supramolecular Filamentous Peptides: Balance of Nanostructure, Cytotoxicity and Antimicrobial Activity. Chem. Commun. 2015, 51 (7), 1289-1292.

(50) Matsuzaki, K. Control of Cell Selectivity of Antimicrobial Peptides. Biochim. Biophys. Acta, Biomembr. 2009, 1788 (8), 16871692.

(51) Tam, J. P.; Lu, Y.-A.; Yang, J.-L. Antimicrobial Dendrimeric Peptides. Eur. J. Biochem. 2002, 269 (3), 923-932. 